Article

\title{
Assessing Employee Engagement in a Post-COVID-19 Workplace Ecosystem
}

\author{
Martyna Joanna Surma ${ }^{1, *(\mathbb{D})}$, Richard Joseph Nunes ${ }^{1}\left(\mathbb{D}\right.$, Caroline Rook $^{2}$ and Angela Loder ${ }^{3}$ \\ 1 Department of Real Estate and Planning, Henley Business School, University of Reading, Whitenights, \\ Reading RG6 6UD, UK; r.j.nunes@reading.ac.uk \\ 2 Department of Leadership, Organisations and Behaviour, Henley Business School, University of Reading, \\ Greenlands, Henley-on-Thames, Reading RG9 2AU, UK; c.rook@henley.ac.uk \\ 3 International WELL Building Institute, New York, NY 10001, USA; angela.loder@wellcertified.com \\ * Correspondence: m.j.surma@pgr.reading.ac.uk
}

check for

updates

Citation: Surma, M.J.; Nunes, R.J.; Rook, C.; Loder, A. Assessing

Employee Engagement in a Post-COVID-19 Workplace

Ecosystem. Sustainability 2021, 13,

11443. https://doi.org/10.3390/

su132011443

Academic Editors: Chihiro Shimizu,

Franz Fuerst, Nikodem Szumilo,

Georgia Warren-Myers, Xiangyu Guo and Hiroki Baba

Received: 31 August 2021

Accepted: 12 October 2021

Published: 16 October 2021

Publisher's Note: MDPI stays neutral with regard to jurisdictional claims in published maps and institutional affiliations.

Copyright: (c) 2021 by the authors. Licensee MDPI, Basel, Switzerland. This article is an open access article distributed under the terms and conditions of the Creative Commons Attribution (CC BY) license (https:/ / creativecommons.org/licenses/by/ $4.0 /)$.

\begin{abstract}
This article has aimed to better understand employee engagement in a post-COVID19 workplace ecosystem. We identified a knowledge gap in the relationship between employee engagement and the physical workplace environment through an interdisciplinary literature review. We subsequently tested this gap by comparing employee engagement metrics proposed by leading academics in the field of organisational psychology with a sample of commonly used real estate industry approaches to monitoring workplace design/management. We focused specifically on industry-projected post-COVID-19 workplace ecosystem scenarios, and the results suggest that traditional employee engagement metrics and industry approaches to monitoring workplace design and management do not fully reflect the recent shift to hybrid work patterns. We shed light on the implications that this can have on our existing knowledge of "sustainable" property markets in a wider city context.
\end{abstract}

Keywords: post-COVID-19 workplace ecosystem; employee engagement; physical workplace environment; employee engagement metrics; sustainable property markets; workplace tools; hybrid work patterns; home office; health and well-being

\section{Introduction}

The topic of employee engagement emerged at the turn of the 20th and 21st centuries as a novel concept in business [1]. It was further developed by human resources departments and consultants to support organisations' mental capital — 'cognitive and emotional fortitude and strength of the employees' — towards higher economic outcomes [2] (p. 295). This wide interest of researchers continues to be relevant to global studies reporting a low engagement level among European and American employees [3], despite the phenomenon of employee engagement already having been recognised by global organisations as one of the key determinants of their success. In the past twenty years, the concept of employee engagement rapidly evolved, resulting in numerous definitions and associated metrics.

In line with the above interest, for more than a decade, the physical workplace has been perceived as a 'business tool' designed for a financial return far greater than the initial investment [4]. This statement is widely supported by a growing body of research on the impact of physical workplace environments on organisational outcomes, accompanied by global real estate industry and building certification interests (e.g., IWBI; Cushman \& Wakefield; and Leesman) in monitoring workplace design and management. Given that the importance of physical workplace environments increases when some or all work is performed virtually [5], this pre-pandemic observation seems to be even more relevant now; new industry-projected workplace ecosystem scenarios developed by leading global providers of consulting (Deloitte), commercial real estate (Cushman \& Wakefield; CBRE; and IPUT), and design, planning and engineering (ARUP) involve a variety of 
workplaces (both physical and virtual) [6]. However, from a scientific perspective, this can be challenged as it is still not clear how the physical workplace environment impacts employee engagement; the studies on this relationship are limited [7-9] despite a large existing body of research focused on other organisational outcomes (e.g., productivity, performance, job satisfaction, etc.). Hence, there is now a greater need to consider different employee engagement metrics and industry approaches to monitoring workplace design and management that may help businesses and their employees adapt to the 'New Normal' (i.e., blended virtual and physical work environments underpinned by digital technology across the office, home, and/or 'third place' work environments) [10].

Considering there is no common agreement among researchers on the definition of 'workplace', the projected hybrid workplace (i.e., home, office, and third places) makes these considerations even more complex and challenging. All of these issues pose a greater need for re-examining employee engagement in the context of a post-COVID19 workplace ecosystem. For example, a 'work environment' in employee engagement studies (e.g., organisational psychology, human resources, and management) is usually defined as a social environment [11-13] rather than a physical one. On the one hand, this understanding is in line with a large number of research studies in the field which emphasise the importance of social relationships at work (e.g., with a supervisor, colleague, customer, etc.) for better engagement. On the other hand, the predominant preference for a 'social' approach by some disciplines may underestimate the possible value of the physical workplace environment for employee engagement, limiting its actual role as a potential variable. Hence, the interaction between physical and social may be a key factor in future research.

Most research on the workplace focuses on the office workplace environment as a dominant place of work [14-18], which may not fully address total workplace ecosystem considerations [10,19-21]. Similarly, most employee engagement metrics tend to favour the quality of the social (working) environment, job design, resource support, working conditions, corporate culture, and leadership style $[3,13]$. However, considering the projected shift toward hybrid work patterns with the dominance of remote work, virtual relationships may dramatically change the way we conceive of employee engagement, its metrics, and the role of the physical workplace environment. Furthermore, employee engagement metrics do not consider indoor environment studies (e.g., the impact of indoor air quality on performance). Therefore, a process of redesigning the post-pandemic workplace and associated employee engagement metrics, industry approaches to monitoring workplace design, and management will require a more holistic approach, which is accompanied by managers advancing their skills in both physical and virtual settings [22-25].

Further complicating our typically held knowledge regarding employee engagement and the place of work is recent research that confirms how working from home during the COVID-19 pandemic was (for some) effective [26] and improved employee productivity and well-being [27]. The same has been reported in pre-COVID-19 studies [28,29]. However, long-term home confinement during the COVID-19 pandemic can have negative mental and physical health consequences, which in turn can reduce productivity among those working remotely [30]. Therefore, there is a greater demand for metrics that help to evaluate and monitor organisational factors (e.g., employee engagement) in different workplace environments. Extensive research by Microsoft into the pandemic's impact on work practices-'The new future of work' [31] —has highlighted some of the most pressing challenges of this new context, including collaboration and meetings, personal productivity and well-being, and the role of technology and its societal implications. Therefore, we can assume that all these issues may similarly impact employee engagement for those projected to soon be working across a mix of workplaces-or a workplace ecosystem. As such, the roles of managers and business leaders are evolving or are having to adapt to the challenges of remote work; they are seeking employee engagement metrics that enable them to monitor flexibility and productivity in a world where remote work is increasingly the norm. 
However, it remains unclear to what extent industry approaches to workplace design and management are aligned with employee engagement metrics. For example, green building certifications (e.g., LEED and BREEAM) focus on minimising the negative effects of the built environment on external environmental conditions (e.g., air quality); health and well-being certifications (e.g., WELL) support employee mental and physical well-being. Potentially, a 'healthy' workplace design can contribute to 'full engagement' [32] —a broader conception of engagement beyond 'a commitment-based view' to a more 'human-oriented' holistic sense of thriving and well-being. Even though third-party survey providers (linked to the real estate industry, e.g., Leesman) have found a correlation between high performing workplaces and organisational outcomes (e.g., improved employee engagement), the academic research on this relationship remains sparse.

Also, there is extensive scientific literature (e.g., on urban health and environmental psychology) on the positive impact of physical environments on human health and wellbeing [33,34]. Yet, there is little known concerning how internal and external workplace environmental conditions impact engagement. For example, many scholars (e.g., environmental psychology field) have studied how the quality of internal office environments (e.g., office design, physical qualities of the building, etc.) impact general employee job performance (e.g., clean and fresh air improves cognitive thinking, biophilic design and contact with nature reduce work stress, etc.) [7,35-41]. Findings from this workstream have been applied to real estate industry research (specifically in the 'green building' sector), concerned with developing healthy work environments that reduce sick leave and improve the overall performance of workers, as well as helping to increase productivity [42]. These improved indoor environmental factors can contribute positively to employee engagement [43]. Hence, there is scope for greater collaboration between built environment professions [44].

As already observed, a hybrid workplace scenario would affect both real estate markets (e.g., office demand, residential quality, etc.) [45] and future city planning (e.g., transportation infrastructure), which may result in remote workers' preference for suburban regions over core city locations [46]. This trend is especially visible in dense urban agglomerations for higher-income economies [47] (e.g., London, New York City), where there is the greatest demand for remote work. Hence, these issues may not only impact single properties in both residential and commercial markets but also urban planning more generally (e.g., development of healthy communities, access to sustainable infrastructure, etc.).

The implementation of a post-COVID-19 workplace ecosystem and the new role of properties in such a context can potentially contribute to more sustainable cities. For example, the substantial decrease in long daily commute times can have a significant positive effect on $\mathrm{CO} 2$ reduction, helping cities to adapt to ongoing climate change challenges. If the effects of digitalisation on the way people work persists, the physical boundaries of the future workplace will continue to blur, and the distribution of work would be spread between a variety of locations, requiring new policies for both organisations and cities. From a real estate perspective, this creates opportunities to rethink the workplace more holistically as a network of places (e.g., home, office, and third places) underpinned by relevant quality standards (e.g., certification schemes on a district/city level as opposed to single properties).

Altogether, the above trends and developments in the area of monitoring workplace design and management and its crossover with employee engagement suggest the need for a better understanding of (i) the 'workplace' definition for a post-COVID-19 world; (ii) the impact of the physical environment on employee engagement; (iii) employee engagement metrics, and the focus and scope of industry approaches to quality workplace design/management; and (iv) the possible alignment with new industry-projected workplace ecosystem scenarios.

In this paper, we seek to better understand employee engagement in the context of a post-COVID-19 workplace ecosystem. We do so by analysing possible alignments/differences between employee engagement metrics and industry approaches to monitoring workplace 
design and management post-COVID-19 to answer the following two research questions: How do academic employee engagement metrics correspond with industry approaches to monitoring workplace design and management? What are the options for the future development of employee engagement metrics and industry approaches to monitoring workplace design and management considering post-COVID-19 workplace ecosystem scenarios?

Additionally, two key definitions have been adopted for this paper. First, the physical workplace environment is understood in a broader context as a post-COVID-19 workplace ecosystem - a network of physical and virtual places where work occurs, including office, home, third places, and surrounding urban realm. This elaborated definition aims to emphasise greater employee flexibility due to the remote character of work accelerated by the pandemic, as well as the importance of urban realm quality, which matters for enhanced human mobility within the new workplace ecosystem. Industry-projected scenarios of a postCOVID-19 workplace ecosystem are reflected in recent reports illustrating the growing shift toward hybrid work patterns as the norm [10,19-21]. Secondly, employee engagement is defined by Schaufeli et al. [48] as "a positive, fulfilling, work-related state of mind that is characterised by vigour, dedication and absorption"(p. 74). This definition is directly aligned with the Utrecht Work Engagement Scale (UWES), which is a globally recognised tool for the measurement of employee engagement in organisations, not to mention widely adopted by academics (e.g., organisational psychologists). There are other definitions of employee engagement as well (see below), but the one chosen has been widely adopted in academic/industry research. As COVID-19 continues to call into question traditional workplace orthodoxies in terms of definitions of 'workplace' and 'employee engagement', the above issues need to be urgently reconsidered [10], including the development of future engagement metrics/industry approaches.

The following paper is structured as follows: Section 2 presents a theoretical background before an outline of adopted methods in Section 3 and an overview and discussion of our results in Sections 4 and 5. The paper closes with some concluding remarks in its final section.

\section{Theoretical Background}

\subsection{The Workplace and Its Effect on Employee Engagement}

The general aim of complementary building certification schemes available on the global market is to provide better office working environments for their users, with a positive impact on both the external environment (e.g., air quality outdoor) and indoor environmental conditions (e.g., lighting, temperature, noise, etc.), as well as health and well-being $[44,49,50]$. Also, while evidence to date has shown that these certifications can help to achieve upgraded employee work performance (which is linked to engagement), they have been designed specifically for traditional corporate office environments that have been the dominant form of physical workplaces [51]. For example, data from thirdparty survey providers has shown that such high performing workplaces, which prioritise experience and well-being, are linked to employee health, engagement and satisfaction; but this data is limited [52]. Additionally, while many survey providers do have workfrom-home modules, they are primarily designed for more traditional offices that may not fully correspond with the characteristics of home workplace environments [53].

Due to higher construction and fit-out costs for developers and business enterprises who want to meet the certifications' criteria, the highest WELL, BREEAM, and LEED standards are offered predominantly among the prime office real estate sector and global corporations. Therefore, there is a real risk of mid-market commercial office space (a purpose-built office space caters to 'hot-desking' arrangements for employees from a range of different commercial organisations) or alternative workspaces that have been left out of the certification process despite the high standard of some of these properties. Additionally, the current COVID-19 related shift towards a greater need for more distributed workplaces is calling into question the expectation that the traditional office will be the biggest influencing factor in employee health and well-being and performance. The latest research has 
demonstrated the varied success of remote work during the COVID-19 pandemic. That also means that it may be worth examining the metrics that have traditionally been used to measure performance and employee engagement in light of these changes.

For example, a recent academic study of homework within the UK demonstrates that most work was carried out comfortably from home during the COVID-19 lockdown [54]. In contrast to the academic research taken solely within the UK context, the XSF@home Total Workplace analysis elaborated by Cushman \& Wakefield [55] in the global context illustrates some greater concerns related to remote work during COVID-19. For example, $57 \%$ of respondents (EMEA countries) reported a lack of sense of well-being, $48 \%$ a lack of learning, and $55 \%$ struggled with connecting to the company culture of everyday staff engagement. Other industrial research conducted by Leesman [56] demonstrates some differences in employee experience due to the variety of home working settings and work activities. This suggests a greater need for comparative analyses of both home/office workplaces to maximise employee experience in the future.

Both above studies highlight a greater need for flexible, hybrid workplace ecosystems in the future, balancing office and remote work. As already projected by Cushman \& Wakefield [20], 50\% of the workforce will likely be working across a 'Total Workplace Ecosystem', balancing office, home, and third places (e.g., café, library). Furthermore, despite remote work having been practised long before COVID-19 [57], this current shift, which has been accelerated by the pandemic, may lead to more lasting effects on the organisation of work [58] and management practices [59] more broadly. It can be observed that since 2020 most academic research on work has been focused on remote work due to COVID-19 [60,61]. Considering this attention to the conditions of remote work, there is an equally emerging private sector interest in metrics that can effectively contribute to the monitoring of employee engagement remotely. However, employee engagement metrics traditionally do not consider the role of the built environment because they are primarily focused on evaluating social relationships in the workplace.

As outlined above, the link between the physical workplace and employee engagement remains understudied. However, some studies-although limited-report the importance of factors that may link employee engagement with the physical workplace environment, such as individual preferences [40,62-64], flexible work arrangements [65,66], or employee health and well-being conditions [62,67-74]. For example, different workspaces may provide greater opportunities for individual arrangements and the control and support of employee engagement (e.g., access to green space to ensure cognitive refreshment and workplace exercise).

Figure 1 identifies the relevant research streams on the link between employee engagement and the physical workplace environment, to be further explored in the context of a post-COVID-19 workplace ecosystem scenario. Notably, most of the research on the physical workplace environment is investigated by the field of environmental psychology. Hence, more interdisciplinary research with other disciplines (e.g., occupational health, human resources/management, and organisational psychology) can potentially shed new light on this relationship and make it more holistic and explanatory. For example, there is a greater need for new studies on both indoor and outdoor environments, and the extent to which employee engagement varies between these different environments for different workplaces (e.g., the role of healthy communities, access to green space, availability of sustainable infrastructure, quality of residential sector, satellite offices' location, etc.).

Hence, further research is needed to explore employee behaviours conducive to better engagement (e.g., recovery experience) considering various types of physical workplace environments and managerial practices. For example, Figure 1 demonstrates that the role of work stress recovery is not addressed in typical environmental psychology work. Additionally, health and well-being must be a transdisciplinary consideration considering the extent to which it may be informed through recovery. Hence, positioning a definition of the 'workplace' within the context of a new post-COVID-19 workplace ecosystem may help to better explain the actual role of these factors. 


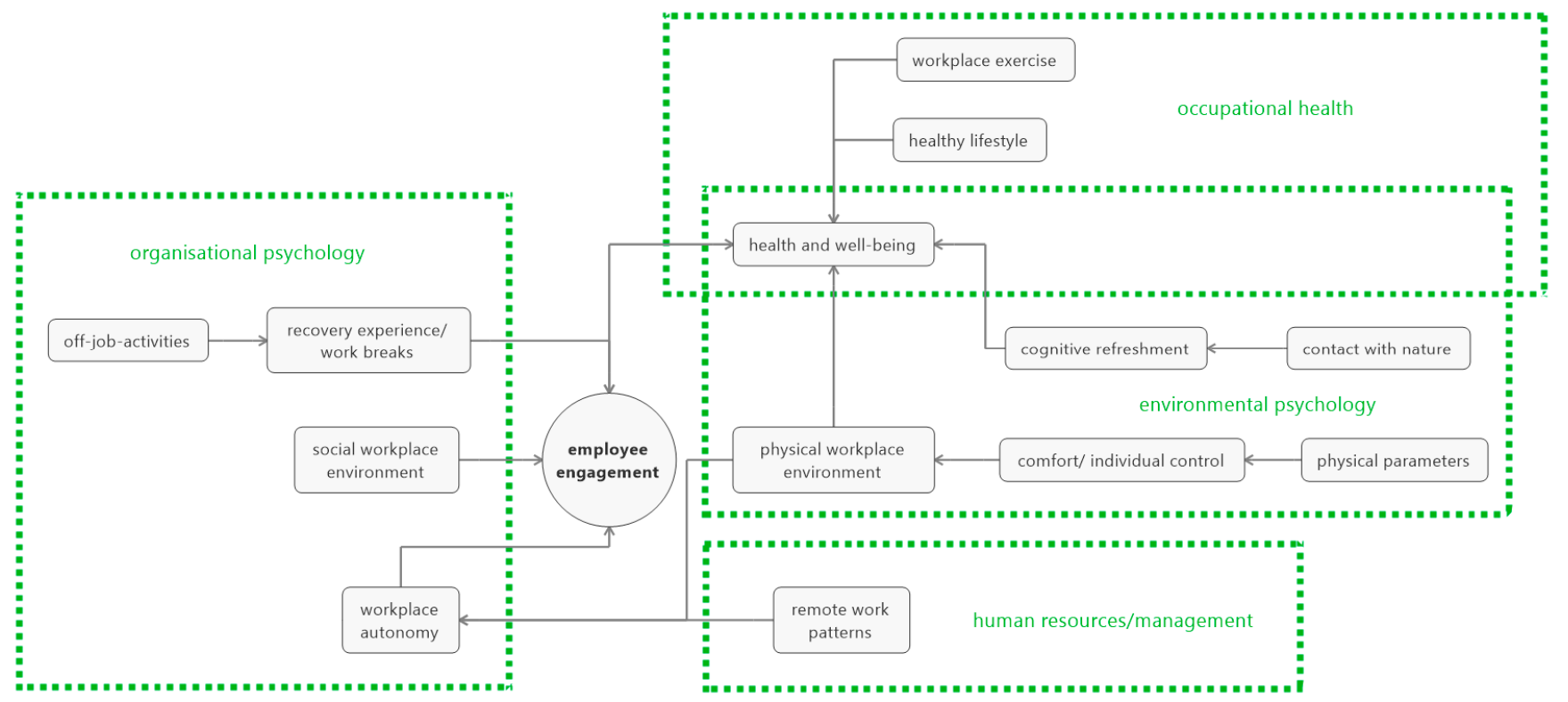

Figure 1. The academic approach for employee engagement.

\subsection{Defining the Post-COVID-19 'Workplace'}

As a result of the COVID-19 pandemic, there has been a shift towards more mobileoriented forms of work supported by the newest technology advances. The acceleration of 'work (from) anywhere' was reported in 2020 by global real estate agencies worldwide, and remote work is expected to continue in the future. These new considerations contribute to a different understanding of the 'workplace' and, therefore, growing demand for new definitions. The certification schemes for setting standards that have been traditionally used by the real estate sector (e.g., WELL; BREEAM; and LEED) are focused on the traditional office workplace environment. The acceleration of new workplace cultures within the wider urban environment, post-COVID-19, can help to redefine the 'workplace' and shift the metrics used to measure employee engagement alongside different workplace considerations. Consequently, there is a need for a new typology of space that is relevant to industry visions of future workplace scenarios, against the long tendency to link workplace design with employee performance within the traditional office $[75,76]$.

For example, a new approach for the workplace ecosystem already has been proposed by IPUT / ARUP. The global research report 'Making Place: The Recalibration of Work, Life, and Place' [19] introduces 'workplacemaking', understood as a concept between traditional workplace design and public realm placemaking. According to this approach, digitalisation has blurred physical boundaries that have resulted in greater consideration of the quality of public and semi-public urban realm 'between the office and the home'. In this context, the meaning of 'working from the office and the home' is understood more broadly than the traditional considerations of office and home design. That is, there has been a shift of industry focus from the building to the neighbourhood/city-scale where it concerns 'workplacemaking', including third places open to the public (e.g., the coffee shop and the library).

A second report, "The Future of Workplace: How will COVID-19 and data shape the new workplace ecosystem?' by Cushman \& Wakefield [20], presents the concept of 'total workplace ecosystem'. Again, the 'workplace' is not defined as a single building or destination, but rather as a network of virtual and physical places, spread between digitally connected homes, offices, and third places (e.g., the café or library). The projected ecosystem aims to provide flexible and on-demand places to support convenience, functionality, and well-being. According to this approach, the workplace can be chosen by an individual employee based on current needs, preferences, workload, job character, etc. The concept is 
illustrated as a city-wide network of spaces, including (1) the home, (2) local community hubs, (3) on-demand event spaces, (4) third places, and (5) core office urban hubs.

A third example is the report 'Real Estate Strategy Asset: 8 Core Truths Guiding the Future of Work' released by CBRE [21]. The authors propose the 'hybrid workforce network' model. The concept emphasises the fluidity in work styles (accelerated by the pandemic), which may potentially impact the future of work and associated corporate real estate strategies. According to this model, the future workplace will reflect the distributed workforce needs, and therefore will be spread among a network of headquarters in urbancore locations and a network of other locations (satellite office networks, homes, project offices, meeting on-demand, flexible spaces, and gyms/cafés). The high-density urban-core locations will be used part-time to facilitate social interactions, and a network of other locations (e.g., satellite offices) will be used to conduct the work closer to home. The 'hybrid workforce network' model aims to decrease both commute times and feelings of isolation associated with remote work, allowing a fluid virtual workplace. Additionally, the proposed CBRE 'hybrid workforce network' model is focused on company-provided locations out of the urban core. This can potentially enhance the general quality of the urban realm, underpinned by the previously mentioned 'workplacemaking' debate by IPUT/ARUP.

The last insight on the future of the workplace has been provoked by Deloitte in the report 'Designing adaptive workplaces: How the public sector can capitalise on lessons learned from COVID-19' [10]. The authors proposed a model of 'adaptive workplaces' as a more fluid concept between onsite and telework, 'for a workforce that is able to work from anywhere but is empowered to work from where they're most productive' (p. 3). In practice, organisational leaders aim to engage employees in shaping their optimal work environments according to individual preferences. The 'adaptive workplaces' model is designed according to four core dimensions: places + spaces, productivity + performance, workforce experience, and well-being and connection. There is an emphasis on employee needs that lead to organisational outcomes. For example, the 'places + spaces' factor is dependent on individual employee engagement levels relative to different workplace settings, which have implications for 'productivity + performance'. Hence, the workplace experience should embrace different workplace dimensions holistically—work, organisation, workforce, technology, and well-being across a variety of places.

Furthermore, recent surveys emphasise the willingness of employees to continue remote work after COVID-19 lockdowns are relaxed. These newly emerging global trends in remote work, supported by advances in ICT support, create a solid background for new debates on the future of work and the 'workplace' in a hypermobile society. These reports by prominent urban real estate and planning consultancies (e.g., IPUT / ARUP, Cushman \& Wakefield, CBRE, and Deloitte) have begun to make significant inroads into a future of work that is distributed across different work environments in the home and in the office and other 'hot-desking' or temporary office arrangements closer to home. All industry reports encourage us to think differently about the 'workplace', its physical dimensions, and its role in ensuring employee engagement, productivity, and well-being.

\subsection{The New Workplace Ecosystem: Implications for Monitoring Employee Engagement Post-COVID-19}

Academic definitions of employee engagement differ from those elaborated by industry organisations across the 'grey' literature [77], resulting in numerous approaches to measuring engagement effectively. Nevertheless, one of the most cited academic definitions of employee engagement was proposed by Kahn [78] as 'the harnessing of organisation members' selves to their work roles; in engagement, people employ and express themselves physically, cognitively, and emotionally during role performances' [78] (p. 694). Employee engagement also has been defined as 'a positive, fulfilling, work-related state of mind that is characterised by vigour, dedication, and absorption' [48] (p. 74), one step up from commitment [79], a passion for work [80,81], or a 'positive work-related psychological state characterised by a genuine willingness to contribute to organisational success' [82] (p. 5); 
a relationship with employee work, role and organisation, or 'a state of mental energy' that is 'associated with involvement, commitment, passion, focused effort and energy' [2] (pp. 295-299).

In the field of organisational psychology, there are numerous metrics focused on employee engagement that have some relevance for employee health and well-being. For example, the Utrecht Work Engagement Scale (UWES) uses 'vigour' as one out of three proposed subscales to measure engagement. As 'vigour' can be defined as either strength, energy or enthusiasm [83], it can be logically linked with employee mental and physical health conditions, which constitutes the efforts around healthy workplace design (both sociologically and physically). Moreover, the UWES methodology is commonly used in various studies on the association between employee engagement and health outcomes [67]. Additionally, linking employee engagement with human health at the workplace can 'empower the workforce and sustain their well-being', as highlighted in Deloitte's model [10] in the context of 'adaptive workplaces' in a post-COVID-19 scenario. However, this approach demands further investigation of the relationship between the physical workplace environment and employee engagement and a closer look at the metrics subsequently developed by both academics and industry, particularly for workplaces that aim to promote health and well-being.

The more distributed workspaces and the acceleration of remote work patterns in a post-COVID-19 world are expected to have a greater impact on employee flexibility associated with employee engagement [10], which may differ across a variety of workplaces. Additionally, employees will have the privilege of choosing their preferred workplace within such an ecosystem based on, for example, individual-level engagement. Hence, there will be a greater role of employee decision-making in the shaping of 'adaptive workplaces'. As little is known about how different workplace settings in the 'total workplace ecosystem' impact employee engagement, further research is needed to address the whole spectrum of workplaces to thoroughly examine this issue.

Although there is no scientific evidence that a 'healthy' workplace design (e.g., WELLcertified office space) directly contributes to employee engagement, some studies report that both physical and mental health factors have a positive relationship with engagement $[67,68]$ (it has to be noted that WELL includes policy, design and maintenance features, but this paper focuses on the design side). However, there are many overlapping factors influencing engagement; so, it is hard to pinpoint which factors influence engagement, as well as how to measure it [44]. Is it the access to natural light or the ability to rest that influences the outcome? Or is it management? Or is it both? The evidence is still emerging and needs clarity on which factors influence what and the extent of their interaction.

Given the fact that employee engagement is driven by a variety of factors (e.g., social relationships at the workplace), enhanced employee mental and physical health conditions can potentially mitigate the negative impact of other factors determining engagement at the workplace. For example, employee engagement as a concept in literature is often referred to as both a healthy workplace [84] and employee health and well-being [85,86]. Hence, a 'healthy' workplace can be understood holistically as a 'healthy' social and physical environment. Nevertheless, there is now a greater need to investigate the role of employee behaviours (e.g., health-oriented ones, see Jindo et al. [70]), and the organisational practices of 'empowering workforce [employees] and sustaining their well-being' in a variety of 'adaptive workplaces' [10]—not to mention their contribution to engagement. The managerial aspect of these roles can be even more challenging considering the projected dominance of remote work patterns in the future.

To sum up, this section demonstrates that the construct of engagement has been strongly conceptualised on the organisational level (e.g., psychological states, job design, leadership, organisational and team factors, and organisational interventions) [87]. Although the qualities of the physical workplace environment and their potential impact on general employee performance have been widely studied in the built environment field, these investigations have been limited to the traditional office environment [7,35-41]. Given 
the above discussion of a new post-COVID-19 workplace ecosystem scenario, traditional office environment-based assumptions of employee engagement need to be reconsidered. For example, Kahn [78] argued that 'personal engagement' with work is determined by experiences within the working environment. But how do employee experiences informing engagement differ across a variety of workplaces?

\section{Methods}

Our research adopted a qualitative mixed-methods approach that has been structured on a combination of critical reviews of literature ('grey' / academic) and the content analysis of (1) workplace design and management monitoring tools, and (2) employee engagement metrics (Figure 2).

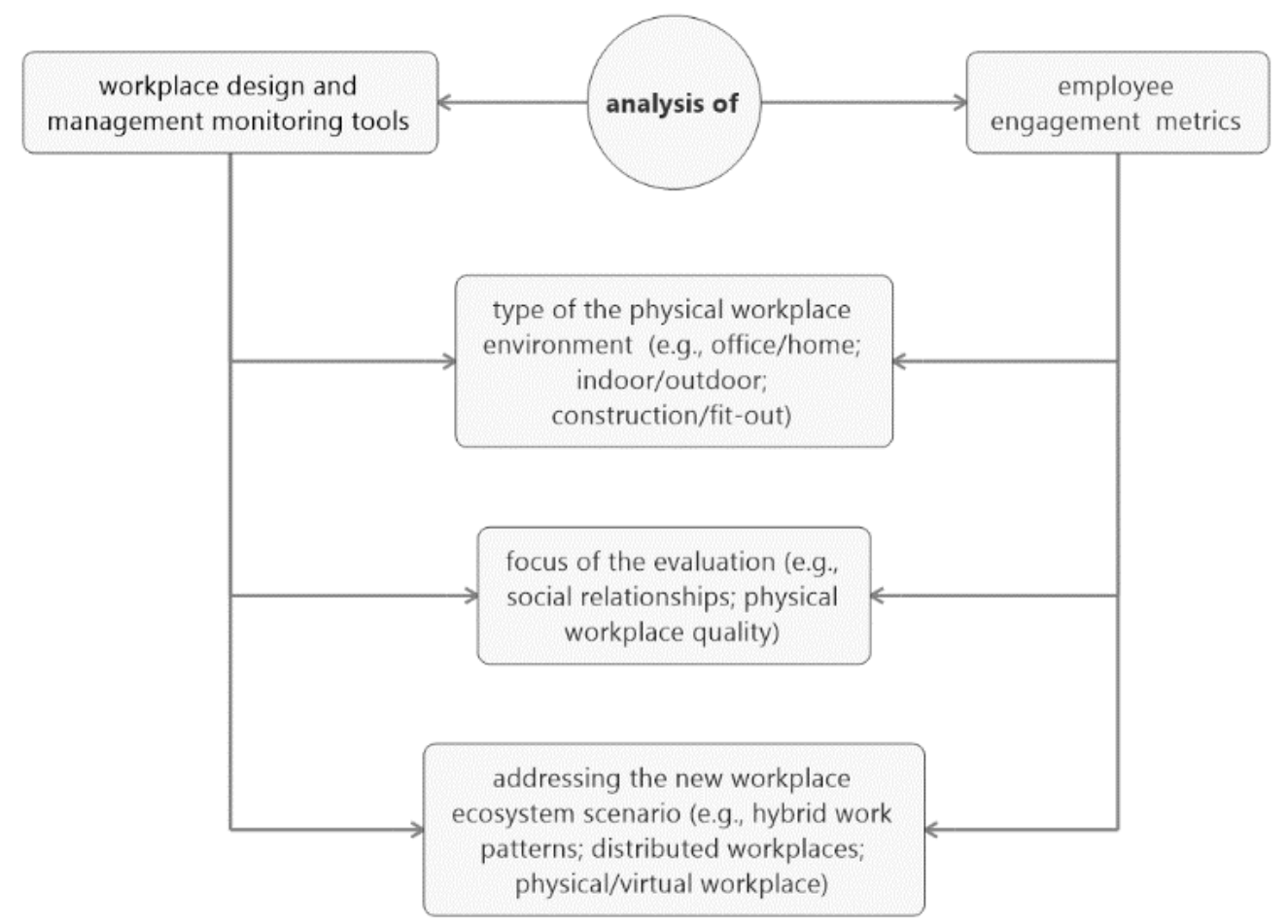

Figure 2. Analytical framework.

First, a critical in-depth review of key global industry reports (Cushman \& Wakefield, CBRE, Deloitte, and IPUT/ARUP), exploring the organisational implications from the switch to a new workplace ecosystem scenario, was undertaken to understand how the physical workplace environment has been defined in a post-COVID-19 world. Next, a content analysis was conducted for a sample of workplace design and management monitoring tools. The content analysis sought to understand the importance of workplace factors that may impact employee engagement in a more distributed workplace ecosystem. The study investigated two types of workplace tools: focusing on office building certifications (WELL and BREEAM) and associated IT infrastructure (WiredScore), and post-occupancy workplace evaluation of 'employee experience' (Leesman) and well-being (Thrive Global) at the workplace. They have been primarily chosen due to their global popularity among organisations within and outside the real estate sector. Additionally, their practice reflects the latest academic and industry research and provides a broad overview of different key aspects of the contemporary workplace, including sustainability assessment methods and green building rating schemes for office building construction, retrofits and fit-outs (BREEAM), digital connectivity and smart technology certification systems (WiredScore), tools for advancing employee health and well-being in buildings (IWBI), behaviour change technology platforms (Thrive Global), and tools for measuring 'employee experience' at workplace (Leesman). Hence, we evaluated a range of factors that may potentially con- 
tribute to better organisational outcomes (e.g., employee engagement). This information was primarily gathered through official company websites (e.g., industry reports). Next, we reflected on all these workplace tools to identify factors conducive to a successful workplace environment that may or may not be relevant in a post-COVID-19 scenario. It should be noted that cerification standard like WELL (organisational AND building focused) or BREEAM (building focused) use metrics to measure the success/outcomes of the actions undertaken for the sake of the certification. However, WELL is not metrics per se; it has features which are evidenced-based that indicate the outcomes will support health/performance (exceptions are some performance-testing standards for indoor environmental quality), and asks projects to use metrics to evaluate these human outcomes (ideally with a third party survey provider for human outcomes, performance-testing agents for environmental outcomes).

Second, a literature review of key academic papers in the field of organisational psychology was undertaken to better understand the practice of evaluating employee engagement by organisations worldwide [79,88-92]. A content analysis of employee engagement questionnaires was conducted to determine the extent or range of workplace factors presented. The analysed employee engagement metrics have been classified by us as 'academic' because they were primarily developed by organisational psychology researchers. However, it must be noted that some of these metrics have been successfully commercialised (e.g., Gallup). Lastly, a matrix of employee engagement metrics and workplace design and management monitoring tools was developed. This was followed by an investigation of the similarities and differences between them, the extent to which they refer to a more distributed workplace ecosystem, and their potential utility in evaluating a variety of workplaces.

\section{Results}

\subsection{The New Workplace Ecosystem: Typology of Space}

Figure 3 presents an elaborated typology of space for the new workplace ecosystem in the context of global industry concepts and industry metrics available on the market. Considering global projections of 'work [from] anywhere' (IPUT / ARUP, Cushman and Wakefield, CBRE, and Deloitte), it can be observed that understandings of workplace environments vary across the industry. For example, recent 'post-COVID-19 workplace ecosystem' definitions, emphasising the importance of the wider urban environment and a mix of spaces (urban realm, third places, and home), is not fully addressed by workplace design and management monitoring tools evaluated in this paper. Still, there is a strong focus on the traditional office building as the dominant physical space where work occurs. Although the internal office environment remains a core focus of all workplace tools, some of them (e.g., WELL and BREEAM) recognise outdoor environmental quality albeit limited to nearby office surroundings (the crossovers between LEED and BREEAM environmental certifications and the WELL Community Standard were not included in this study). Also, some industry leaders (e.g., Leesman)—in the pandemic context—have recently gained interest in the home environment and its evaluation. And while Thrive Global does not aim to evaluate workplace design and management, its tool could potentially be adapted to monitoring employee health and well-being in the office, third places, and home.

Still, the factors assessing physical home environments may need further investigation as they are often limited to standard office workplace designs (e.g., availability of desk, chair, etc.). Additionally, the recent shift to remote work highlights the importance of virtual workplace quality and related digital infrastructure (WiredScore) for both office and home environments. That is, this trend can potentially enhance and support remote work tendencies within the wider urban realm (e.g., third places), requiring the adaptation of new digital tools like those offered by Thrive Global to measure organisational factors (e.g., employee engagement metrics) for different places of work. 


\section{THE NEW WORKPLACE ECOSYSTEM}

TYPOLOGY OF SPACE

concepts
IPUT/ARUP
CUSHMAN \& WAKEF
CBRE
DELOITTE
WELL
BREEAM
LEESMAN
WIRED SCORE
THRIVE GLOBAL

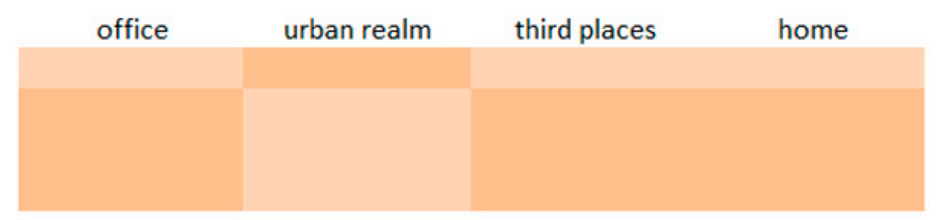

workplace design and management monitoring tools

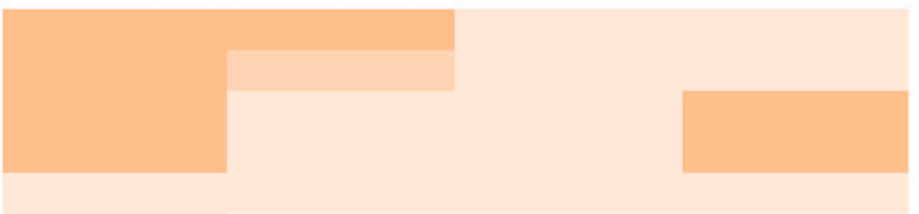

more focus

less focus

no focus

Figure 3. A typology of space considered by the industry for the new workplace ecosystem.

\subsection{Workplace Tools}

Our content analysis of workplace design and management monitoring tools has demonstrated that the most developed and comprehensive standards for the traditional office workplace are currently represented in the WELL certification by IWBI. While some of its factors of assessment (e.g., water, materials) overlap with BREEAM standards by BRE, there is a slightly different focus to these two certification schemes. For example, the BREEAM assessment emphasises the positive relationship of physical workplaces to their external environments (i.e., green buildings), whereas WELL gives priority to employees' health and well-being.

Generally, such workplace tools are aligned with sustainability requirements for green buildings, which is favoured by organisations like the World Green Building Council. However, sustainability requirements have started to add health-focused distinctions. This can be observed on several levels: physical workplace quality (i.e., air, water, materials, light, thermal comfort, and sound), healthy behaviours among employees (i.e., nourishment, movement, and mind), and organisational health policy (i.e., community or social interaction). In WELL, the risk reduction model for the sick building syndrome has been expanded to also include health and well-being promotion approaches [44]. Hence, the approach proposed by both WELL and BREEAM emphasises the greater need for a more holistic workplace design (e.g., considering indoor and outdoor environment quality and employee health and well-being). Considering recent industry projections of a post-COVID-19 shift to work in an extended workplace ecosystem, there is consequently a growing need to holistically embrace both internal and external urban qualities across this new typology of interconnected workplaces.

As argued by real estate advisors, prevailing workplace trends will be driven by a variety of factors such as existing housing quality and space, cultural differences, laws, and regulations. Nevertheless, the workplace flexibility associated with work from home has been highlighted as key to promoting a healthy work environment, which may also positively impact employee engagement [93].

In conclusion, the influencing factors underpinning health and well-being (e.g., WELL) and sustainability (e.g., BREEAM) in the workplace may need further exploration within the wider city context of a post-COVID-19 workplace ecosystem. For example, the relationship 'employee-to-workplace' outlined in real estate industry trends requires additional investigation (e.g., indoor environmental quality) as it may constitute a missing component of employee engagement metrics. Moreover, there is now a greater need to develop 
'home-to-outdoor environment' metrics (e.g., Leesman), as well as a need to identify the associated factors determining employee engagement in such contexts. For example, the research conducted by Carmona et al. [54] already highlights the importance of both internal and external environmental conditions for the home workplace environment. However, in the case of the Leesman Index, the environmental assessment is focused on indoor evaluation [53]. Although it is detailed and wide in scope, there is a greater need for consideration of the interplay of external environmental parameters at the city scale (e.g., access to green space, mixed-use development, less-trafficked streets to enable walking and cycling, and connected neighbourhoods).

\subsection{Employee Engagement Metrics}

Our content analysis of employee engagement metrics demonstrates a strong focus on evaluating employee attitudes, feelings and behaviour toward work performed. Some of these metrics look at employee relationships with co-workers/customers [89], their line manager [91], and the organisation [79,92]. Therefore, priority is often given to the evaluation of social relationships that impact employee engagement in the workplace. The next section will present the identified differences and alignments between the abovementioned workplace tools and employee engagement metrics.

\subsection{Matrix of Metrics/Tools: Differences/Alignments}

The comparative analysis of both academic employee engagement metrics and workplace design and management monitoring tools is a necessary step if we are to better understand different levels of relationships measured and evaluated by them. Figure 4 illustrates a matrix of metrics/tools. Our analysis suggests organisational psychology approaches to employee engagement are predominantly focused on the relationship between employees and work (5). However, it is not clear how the physical workplace contributes to engagement. That is, there is a broad spectrum of social relationships (2-4) in the workplace, which informs employee engagement (relationship with co-workers, customers, and supervisors), not to mention wider considerations such as organisational culture (1). For example, we find that employee engagement metrics and workplace tools emphasise different factors in their assessment of employee-to-work relationships (Figure 4).

As such, the alignment between employee engagement metrics and workplace tools is weak. This primarily reflects the substantial lack of academic research on this relationship. However, Figure 4 demonstrates that workplace tools are advanced and expand from the physical (e.g., work equipment, digital connectivity, and workplace design) to the more human-oriented dimensions of workplace evaluations (e.g., employee health and wellbeing, family relationships, and organisational policy). It can be observed that employee engagement metrics developed in the field of organisational psychology are strongly dominated by human relationship assessments, leaving the physical characteristics of workplace environments left out of consideration.

Nevertheless, the growing popularity of prime office certification schemes (e.g., WELL, BREEAM) and 'employee experience' tools (e.g., Leesman) suggest there is an appetite for a more integrated assessment of physical workplace environments (indoor and outdoor), as well as organisational engagement [7]. These more holistic approaches to assessment would need to encompass both physical and social factors. The challenge is understanding how 'employee experience' across the physical workplace ecosystem can be translated into engagement metrics. 


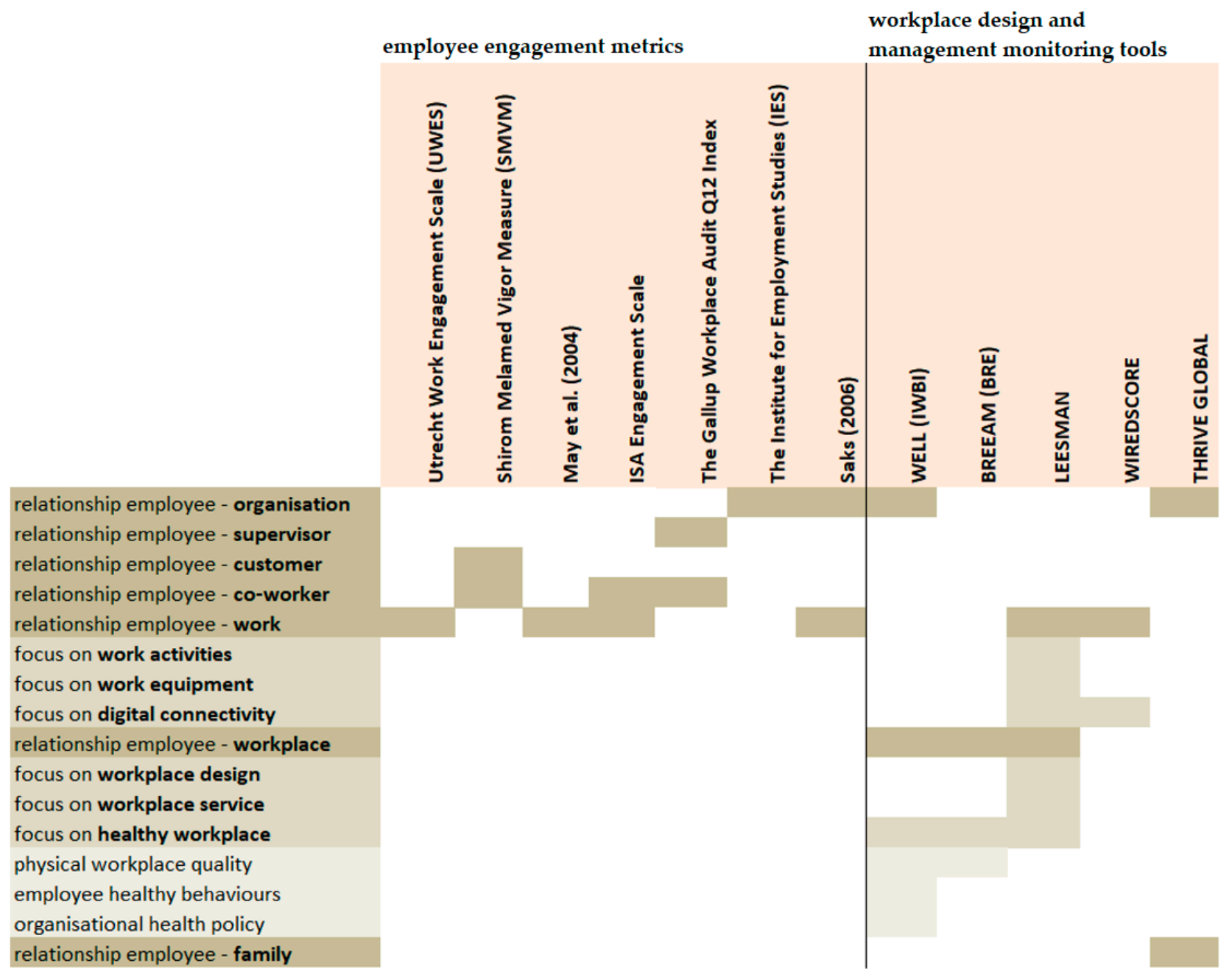

Figure 4. Different-level employee relationships evaluated in employee engagement metrics and workplace tools.

\subsection{Matrix of Metrics/Tools: The New Workplace Ecosystem Scenario}

Based on our analysis, industry considerations of a variety of workplaces within a workplace ecosystem scenario must consider an expanded set of metrics/tools. Figure 5 illustrates how existing employee engagement metrics and workplace design and management monitoring tools are aligned with a post-COVID-19 workplace ecosystem scenario. It can be observed that employee engagement metrics were designed for a traditional office environment while workplace tools already have expanded to post-COVID-19 home office evaluations. Still, the third places sector remains left out of certification schemes. Despite industry evaluations of the neighbourhood level, a wider scale of assessment that factors in 'flexible workplace' arrangements is still needed. For example, this may require the expansion of existing metrics to encompass satellite offices at the city scale, including access to infrastructure that is underpinned by a high-quality urban realm (i.e., 'workplacemaking') [19].

However, all of this requires substantial changes in the way we define 'employee engagement' and 'workplace'. First, employee engagement metrics would need to factor in a variety of workplaces (including virtual workplaces) and the substantial changes to levels of social interaction and related managerial practices associated with this consideration. Given the projected shift toward hybrid work patterns, the definition of employee engagement may need to be reconceptualised to adequately capture a new dynamism of work in different work settings. Secondly, the physical workplace transition may require 
new tools or the modification of existing ones to evaluate a whole spectrum of workplaces (e.g., home, core office, and satellite office) within a wider urban setting.

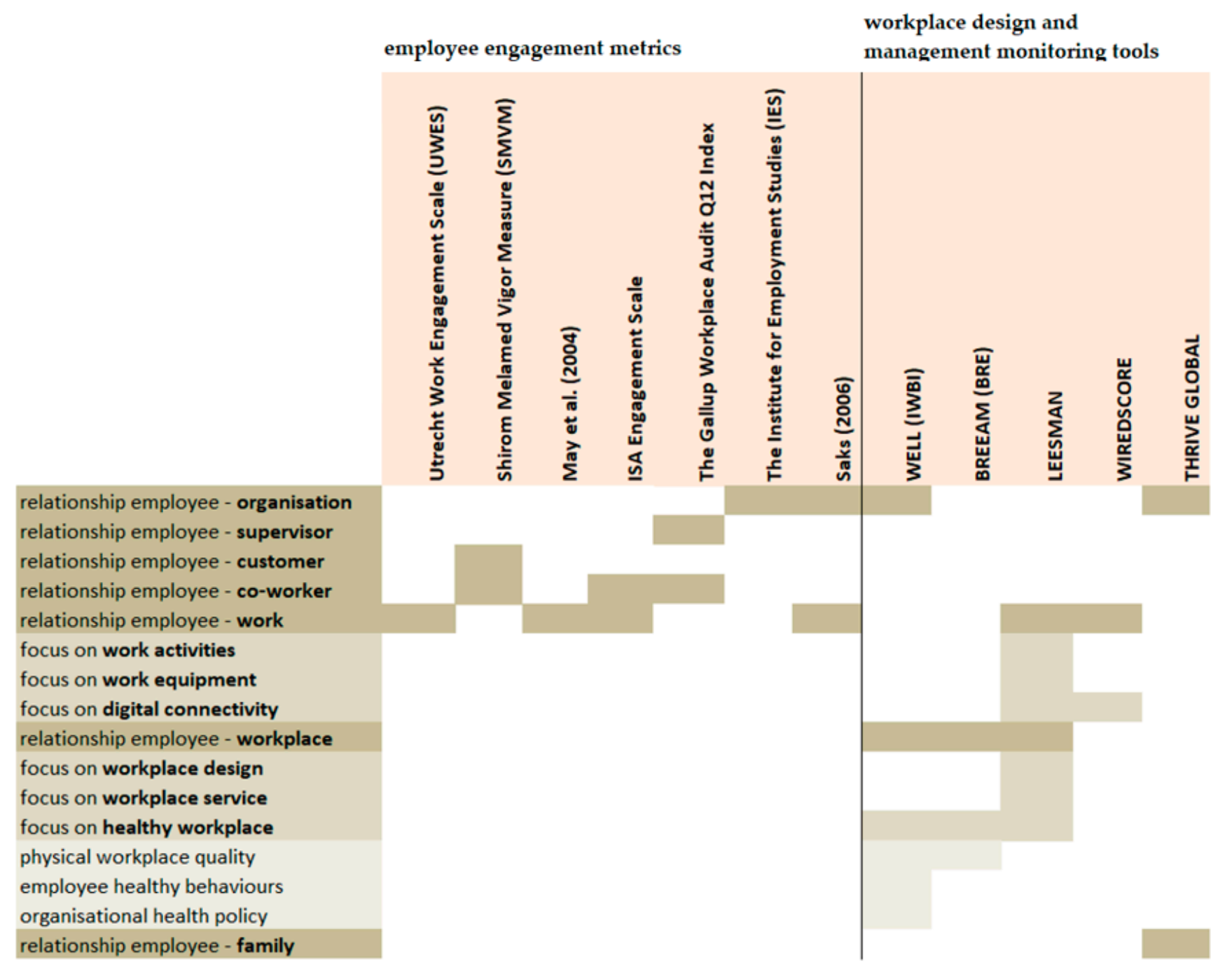

Figure 5. Matrix of metrics considering the new workplace ecosystem scenario.

\section{Discussion}

Given the growing interests of both the global real estate industry (e.g., IWBI, BRE, Cushman and Wakefield, Leesman, etc.) and business consultants in workplace design, evaluation, and management for improved organisational outcomes (e.g., productivity, performance, etc.), our study has explored the extent to which employee engagement metrics correspond with workplace design and management monitoring tools. It has sought to better understand the potential gaps and alignments between the two. The discussion below draws on the insights of both academic and industry research, aiming to provide new perspectives on employee engagement metrics and workplace tools in a post-COVID-19 world.

The above review of organisational psychology approaches to employee engagement has highlighted the importance of social factors for better engagement in the workplace. Though, the physical workplace is not seen as a variable environment but rather treated as a constant. This is consistent with academic studies in fields such as environmental psychology, which are limited regarding the actual role of the physical environment for employee engagement [7]. On the one hand, this contrasts with the large body of research emphasising the importance of the physical environment in determining organisational 
outcomes (e.g., productivity, performance, etc.). On the other hand, this is aligned with the disconnect of employee engagement metrics and workplace design and management monitoring tools.

We have pointed out the strong focus of employee engagement metrics and workplace tools on the traditional (office) workplace environment as the dominant place of work. However, the current organisational shift (caused by the COVID-19 pandemic) toward more hybrid-oriented ways of working has forced a reconsideration of the workplace. This shift is most currently reflected in industry evaluations of the home office environment. Yet, our analysis of workplace tools confirms there are substantial limitations with their ability to comprehensively address industry-projected post-COVID-19 workplace ecosystem scenarios.

Also, we have found that workplace tools are predominantly focused on indoor characteristics without equivalent attention to outdoor urban environmental factors. This contrasts, for example, with recent research that emphasises the importance of both indoor and outdoor environmental factors for home offices [54]. Despite the advanced level of certification schemes, including issues such as employee health and well-being (WELL), green building design (BREEAM), and digital connectivity (WiredScore), industry certification schemes still lack a city-wide scale of assessment.

Given that future post-COVID-19 workplace scenarios must be understood in a much wider built environment context, this demands greater concern around supporting city infrastructure. This may require continuing with efforts aimed at mitigating urban sprawl and rising prices in the suburbs [46]. Hence, to ensure sustainable property markets, it seems relevant to consider a greater distribution of mixed business and residential districts or nodes across a city-region, underpinned by active transportation infrastructure (e.g., pedestrian routes, bicycle paths, etc.).

However, more research is needed to determine the extent to which different types of physical spaces impact employee engagement and what these flexible work arrangements mean for the sustainability of property markets. Moreover, considering how social relationships have dramatically changed during the COVID-19 pandemic (e.g., virtual workplace), there is a need to closely examine human-space interactions. Hence, addressing these physical and social factors will be essential considering a wider adoption of remote work patterns in the future workplace and its future impact on property markets.

\section{Conclusions}

In this paper, we have explored the possible impact of the built environment on employee engagement in a post-COVID-19 world in which changes to the way we work have been triggered or reinforced. That is, the necessity of remote work has accelerated a global debate on the possibilities of adopting home, office, and remote work patterns for the future. The discussion has been widely supported by a growing number of industry reports projecting visions of a 'total workplace ecosystem' [20] underpinned by highquality 'workplacemaking' [19] practices that ensure 'adaptive workplaces' [10] for a 'hybrid workforce network' [21]. Hence, we have adopted a 'post-COVID-19 workplace ecosystem' definition to capture this emergent understanding of a physical workplace that embraces both virtual and physical realities across a variety of workplaces.

However, we conclude that existing academic research on the link between the built environment and employee engagement is limited. Yet, considering how early approaches to employee engagement were primarily based on traditional workplace environments, future considerations of different workplace types and their distribution at the city scale, alongside the growing flexibilisation and digitalisation of work, may shed new light on our understanding of employee engagement.

Our analysis of existing employee engagement metrics and workplace design and management monitoring tools demonstrates some divergence between them. On the one hand, traditional academic employee engagement metrics do not recognise the potential impact of indoor environmental quality as they are solely focused on the analysis of social 
relationships at work. But these have been dramatically changed by the acceleration of remote/hybrid work patterns due to the COVID-19 pandemic, as mentioned before. On the other hand, a growing amount of industry research on 'employee experience' in the physical workplace environment encourages organisations to use indoor environmental quality as a proxy for organisational benefits (e.g., better employee engagement). Hence, industry approaches to workplace tools may potentially inform the academic understanding of employee engagement and its metrics, but further research is needed to fully clarify the linkages between the two. For example, high performing buildings are showing promise of better health and employee engagement and performance outcomes, but the exact relationship between the physical versus the social factors is still unclear. Additionally, in light of the total workplace ecosystem post-COVID-19, it may be relevant to consider the 'bigger picture' and to expand existing employee engagement metrics and workplace tools to the city scale (e.g., wide access to Wi-Fi in third places, development of healthy communities, access to green space for cognitive refreshment, satellite offices located nearby residential districts, and sustainable transportation). The above adaptations to the future workplace will certainly contribute to more sustainable property markets.

Lastly, we have been able to illustrate that existing approaches to both employee engagement metrics and workplace tools are still far from considering this emerging workplace ecosystem despite some recent adaptations (e.g., the home environment assessment). We recognise this is a challenging task. Our research demonstrates that this is a complex subject with many variables. Future considerations of workplace ecosystems will inevitably require substantial changes in the way we think about the relationship of 'employee engagement' to the 'workplace'. This paper has aimed to catalyse this transition.

Author Contributions: Conceptualisation, M.J.S. and R.J.N.; formal analysis, M.J.S.; funding acquisition, M.J.S., R.J.N., C.R. and A.L.; investigation, M.J.S.; methodology, M.J.S., R.J.N. and C.R.; supervision, R.J.N., C.R. and A.L.; validation, M.J.S. and R.J.N.; visualisation, M.J.S.; writing-original draft, M.J.S.; writing—review and editing, M.J.S., R.J.N., C.R. and A.L. All authors have read and agreed to the published version of the manuscript.

Funding: The above study was funded by the Accelerating Business Collaboration award granted by the Economic and Social Research Council in the United Kingdom and delivered via the University of Oxford (grant number: ES/V502133/1). The publication fee was financially subsidised by the University of Tokyo.

Institutional Review Board Statement: Not applicable.

Informed Consent Statement: Not applicable.

Data Availability Statement: No new data was created or analysed in this study. Data sharing does not apply to this article.

Acknowledgments: The above study was the result of a 3-month remote placement, undertaken by Martyna Joanna Surma at the International WELL Building Institute (IWBI) in New York City (USA) from January to March 2021 under the supervision of Angela Loder, Vice-President, Research at IWBI. This placement was made possible by the Accelerating Business Collaboration award granted by the Economic and Social Research Council in the United Kingdom and delivered via the University of Oxford (grant number: ES/V502133/1). The paper was based on the presentation given at the Joint Workshop Series on Sustainable Property Markets organised jointly by the University of Tokyo (Center for Spatial Information Science) and The University of Cambridge (Cambridge Centre for Real Estate Research) on 25 June 2021. All authors would like to thank the special issue editors: Chihiro Shimizu (University of Tokyo), Franz Fuerst (University of Cambridge), Nikodem Szumilo (University College London), Georgia Warren-Myers (University of Melbourne), Xiangyu Guo (Fudan University), and Hiroki Baba (University of Tokyo), as well as the two anonymous reviewers for their valuable comments on the original draft. Also, all authors would like to thank the University of Tokyo for funding this publication.

Conflicts of Interest: The authors declare no conflict of interest. 


\section{References}

1. Schaufeli, W.; Salanova, M. Work engagement: An emerging psychological concept and its implications for organizations. In Research in Social Issues in Management, 1st ed.; Gilliland, S.W., Steiner, D.D., Skarlicki, D.P., Eds.; Information Age Publishers: Greenwich, CT, USA, 2007; pp. 135-177.

2. Schaufeli, W.B.; Salanova, M. Burnout, Boredom and Engagement in the Workplace. In An Introduction to Contemporary Work Psychology, 1st ed.; Peeters, M.C.W., de Jonge, J., Taris, T.W., Eds.; John Wiley \& Sons, Incorporated: Chichester, UK, 2014; pp. 293-320.

3. Attridge, M. Measuring and managing employee work engagement: A review of the research and business literature. J. Workplace Behav. Health 2009, 24, 383-398. [CrossRef]

4. USGSA. Workplace Matters; U. S. General Services Administration: Washington, DC, USA, 2006.

5. Deloitte. Elevating the Workforce Experience: The Physical Lens. Available online: https://www2.deloitte.com/content/ $\mathrm{dam} /$ Deloitte/us/Documents/human-capital/us-elevating-the-workforce-experience-the-physical-lens.pdf (accessed on 12 May 2021).

6. Gillen, N.; Nissen, P.; Park, J.; Scott, A.; Singha, S.; Taylor, H.; Taylor, I.; Featherstone, S. Rethink Design Guide: Architecture for a Post-Pandemic World, 1st ed.; RIBA Publishing: London, UK, 2021.

7. Kegel, P. The impact of the physical work environment on organizational outcomes: A structured review of the literature. J. Facil. Manag. Educ. Res. 2017, 1, 19-29. [CrossRef]

8. Appel-Meulenbroek, R.; Clippard, M.; Pfnür, A. The effectiveness of physical office environments for employee outcomes: An interdisciplinary perspective of research efforts. J. Corp. Real Estate 2018, 20, 56-80. [CrossRef]

9. Smith, A. How important is the physical workplace to engagement and productivity? J. Facil. Manag. 2011, 9. [CrossRef]

10. Deloitte. Designing Adaptive Workplaces: How the Public Sector Can Capitalize on Lessons Learned from COVID-19. Available online: https:/ / www2.deloitte.com/xe/en/insights/industry/public-sector/designing-for-adaptive-work-in-the-public-sector. html (accessed on 5 March 2021).

11. Kumar, R.; Sia, S.K. Employee engagement: Explicating the contribution of work environment. Manag. Labour Stud. 2012, 37, 31-43. [CrossRef]

12. Osborne, S.; Hammoud, M.S. Effective employee engagement in the workplace. Int. J. Appl. Manag. Technol. 2017, 16, 50-57. [CrossRef]

13. Rana, S.; Ardichvili, A.; Tkachenko, O. A theoretical model of the antecedents and outcomes of employee engagement. J. Workplace Learn. 2014, 26, 249-266. [CrossRef]

14. Kämpf-Dern, A.; Will-Zocholl, M. Future workspaces. In Proceedings of the Transdisciplinary Workplace Research (TWR) Conference, Frankfurt am Main, Germany, 16-19 September 2020.

15. Devlin, A.S. Environmental Psychology and Human Well-Being: Effects of Built and Natural Settings, 1st ed.; Elsevier Science \& Technology: San Diego, CA, USA, 2018.

16. Veitch, J.A. Work environments. In The Oxford Handbook of Environmental and Conservation Psychology, 1st ed.; Clayton, S.D., Ed.; Oxford University Press: Oxford, UK, 2012; pp. 248-275. [CrossRef]

17. Valentin, J.; Gamez, L. Environmental Psychology: New Developments; Nova Science Publishers, Inc.: New York, NY, USA, 2010.

18. Cooper, R.; Burton, E.; Cooper, C.L. Wellbeing and the Environment, 1st ed.; John Willey \& Sons, Ltd.: Chichester, UK, 2014.

19. IPUT\&ARUP. Global Research Report: Making Place. The Recalibration of Work, Life and Place. Available online: https://www. arup.com/perspectives / publications / research/section/making-place-the-recalibration-of-work-life-and-place (accessed on 3 December 2020).

20. Cushman\&Wakefield. The Future of Workplace: How Will COVID-19 and Data Shape the New Workplace Ecosystem? Available online: https:/ / www.cushmanwakefield.com/en/insights/covid-19/the-future-of-workplace (accessed on 3 December 2020).

21. CBRE. Real Estate Strategy Asset: 8 Core Truths Guiding the Future of Work. Available online: https://www.cbre.com/-/media/ files/the-way-forward/real-estate-reset/real-estate-strategy-reset-2021.pdf (accessed on 24 February 2021).

22. Kane, G.C.; Nanda, R.; Phillips, A.; Copulsky, J. Redesigning the Post-Pandemic Workplace. MIT Sloan Manag. Rev. 2021, 62, $12-14$.

23. Love, A. Fueling engagement in times of crisis. Lead. Lead. 2021, 2021, 32-39. [CrossRef]

24. Kniffin, K.M.; Narayanan, J.; Anseel, F.; Antonakis, J.; Ashford, S.P.; Bakker, A.B.; Bamberger, P.; Bapuji, H.; Bhave, D.P.; Choi, V.K. COVID-19 and the workplace: Implications, issues, and insights for future research and action. Am. Psychol. $2021,76,63$. [CrossRef] [PubMed]

25. Newman, S.A.; Ford, R.C. Five Steps to Leading Your Team in the Virtual COVID-19 Workplace. Organ. Dyn. 2021, 50, 100802. [CrossRef]

26. Hickman, A.; Robison, J. Is Working Remotely Effective? Gallup Research Says Yes. Available online: http://metadataetc. org/gigontology/pdf/Is\%20Working\%20Remotely\%20Effective\%20Gallup\%20Research\%20Says\%20Yes.pdf (accessed on 27 March 2021).

27. Russo, D.; Hanel, P.H.P.; Altnickel, S.; van Berkel, N. Predictors of well-being and productivity among software professionals during the COVID-19 pandemic-A longitudinal study. Empir. Softw. Eng. 2021, 26, 62. [CrossRef] 
28. Bloom, N. To Raise Productivity, Let More Employees Work from Home. Available online: https://stayinthegame. net/wp-content/uploads/2019/07/HBR-To-Raise-Productivity-Let-More-Employees-Work-from-Home.pdf (accessed on 27 March 2021).

29. Hunter, P. Remote working in research. EMBO Rep. 2019, 20, e47435. [CrossRef] [PubMed]

30. Dongarwar, D.; Yusuf, K.K.; Maiyegun, S.O.; Ibrahimi, S.; Ikedionwu, C.; Salihu, H.M. Covid-19 and Neuro-Behavioral Economics: A Conceptual Framework to Improve Physical and Mental Health among Remote Workers. Int. J. MCH AIDS. 2020, 9, 360-363. [CrossRef] [PubMed]

31. Teevan, J.; Hecht, B.; Jaffe, S. The New Future of Work: Research from Microsoft on the Impact of the Pandemic on Work Practices. Available online: https:/ / www.microsoft.com/en-us/research/uploads/prod/2021/01/NewFutureOfWorkReport. pdf (accessed on 28 March 2021).

32. Robertson, I.T.; Cooper, C.L. Full engagement: The integration of employee engagement and psychological well-being. Leadersh. Organ. Dev. J. 2010, 31, 324-336. [CrossRef]

33. Altomonte, S.; Allen, J.; Bluyssen, P.M.; Brager, G.; Heschong, L.; Loder, A.; Schiavon, S.; Veitch, J.A.; Wang, L.; Wargocki, P. Ten questions concerning well-being in the built environment. Build. Environ. 2020, 180, 106949. [CrossRef]

34. Loder, A. Small-Scale Urban Greening: Creating Places of Health, Creativity, and Ecological Sustainability, 1st ed.; Routledge/Taylor \& Francis: London, UK; New York, NY, USA, 2020. [CrossRef]

35. Wyon, D.P. The effects of indoor air quality on performance and productivity. Indoor Air 2004, 14, 92-101. [CrossRef]

36. Clements-Croome, D. Intelligent Buildings: Design, Management and Operation, 1st ed.; Thomas Telford: London, UK, 2004.

37. Kwallek, N.; Soon, K.; Lewis, C.M. Work week productivity, visual complexity, and individual environmental sensitivity in three offices of different color interiors. Color Res. Appl. 2007, 32, 130-143. [CrossRef]

38. Vischer, J.C. The effects of the physical environment on job performance: Towards a theoretical model of workspace stress. Stress Health: J. Int. Soc. Investig. Stress 2007, 23, 175-184. [CrossRef]

39. Chan, J.K.; Beckman, S.L.; Lawrence, P.G. Workplace design: A new managerial imperative. Calif. Manag. Rev. 2007, 49, 6-22. [CrossRef]

40. Feige, A.; Wallbaum, H.; Janser, M.; Windlinger, L. Impact of sustainable office buildings on occupant's comfort and productivity. J. Corp. Real Estate 2013, 15, 7-34. [CrossRef]

41. Chadburn, A.; Smith, J.; Milan, J. Productivity drivers of knowledge workers in the central London office environment. J. Corp. Real Estate 2017, 19, 66-79. [CrossRef]

42. Brinkley, I.; Fauth, R.; Mahdon, M.; Theodoropoulou, S. Is Knowledge Work Better for Us? Knowledge Workers, Good Work and Wellbeing. Available online: https://www.researchgate.net/profile/Sotiria_Theodoropoulou2/publication/274324989_Is_ Knowledge_Work_Better_for_Us_Knowledge_Workers_Good_Work_and_Well-Being/links/551bbc4a0cf2fdce8438a88d/IsKnowledge-Work-Better-for-Us-Knowledge-Workers-Good-Work-and-Well-Being.pdf (accessed on 3 March 2021).

43. Klotz, A.C. Creating Jobs and Workspaces That Energize People. MIT Sloan Manag. Rev. 2020, 61, 74-78.

44. IWBI. Global Research Agenda: Health, Well-Being and the Built Environment. Available online: https://marketing.wellcertified. com/global-research-agenda (accessed on 3 March 2021).

45. Liu, S.; Su, Y. The impact of the COVID-19 pandemic on the demand for density: Evidence from the US housing market. Munich Pers. RePEc Arch. 2020, 207, 110010.

46. Ramani, A.; Bloom, N. The Donut Effect: How COVID-19 Shapes Real Estate. Available online: https://siepr.stanford.edu/sites/ default/files/publications/SIEPR\%20Policy\%20Brief\%20January\%202021\%20v04.pdf (accessed on 26 May 2021).

47. Dingel, J.I.; Neiman, B. How many jobs can be done at home? J. Public Econ. 2020, 189, 104235. [CrossRef] [PubMed]

48. Schaufeli, W.B.; Salanova, M.; González-Romá, V.; Bakker, A.B. The measurement of engagement and burnout: A two sample confirmatory factor analytic approach. J. Happiness Stud. 2002, 3, 71-92. [CrossRef]

49. IWBI. People + Planet. Applying BREEAM and the WELL Building Standard. Strategies for Interiors, New Buildings and Existing Buildings Seeking Dual Certification. Available online: https://a.storyblok.com/f/52232/x/295390c52f/breeam_wellv2-crosswalk_q2-2021.pdf (accessed on 7 February 2021).

50. BRE. Assessing Health and Wellbeing in Buildings. Alignment between BREEAM and the WELL Building Standard. Available online: https: / / tools.breeam.com/filelibrary / Briefing\%20Papers/BREEAM-Briefing---Assessing-Health-and-Wellbeing-inBuildings---January-2017--93678-.pdf (accessed on 31 January 2021).

51. Leesman. The World's Best Workplaces 2019. Unpacking Lessons from the Top. Available online: https://www.leesmanindex. com/media/LeesmanInsights-Book-SP-2019-Digital.pdf (accessed on 21 September 2021).

52. Leesman. The Workplace Experience Revolution. Part 2: Do New Workpalces Work. Available online: https://www. leesmanindex.com/media/Leesman-EwX-P2-Second-Digital-Edition.pdf (accessed on 21 September 2021).

53. Leesman. The Home Working Impact Code. Available online: https://www.leesmanindex.com/media/Leesman-Impact-CodeHome-31.03.21.pdf (accessed on 8 May 2021).

54. Carmona, M.; Giordano, V.; Nayyar, G.; Kurland, J.; Buddle, C. Home Comforts: How the Design of Our Homes and Neighbourhoods Effected Our Experience of the Covid-19 Lockdown and What We Can Learn for the Future. Available online: https:/ / www.housinglin.org.uk/_assets/Resources/Housing/OtherOrganisation/Report_Home-Comforts-Report.pdf (accessed on 3 December 2020). 
55. Cushman\&Wakefield. Purpose of Place: History and Future of the Office. Available online: https://www.cushmanwakefield. com/en/insights/covid-19/the-future-of-the-office-space (accessed on 3 December 2020).

56. Leesman. Your Workplace of the Future: All You Need to Know to Plan Your Future Workplace Strategy. Available online: https:/ / www.leesmanindex.com/media/Leesman-Your_Workplace_of_the_Future-SP.pdf (accessed on 8 December 2020).

57. Olson, M.H. Remote office work: Changing work patterns in space and time. Commun. ACM 1983, 26, 182-187. [CrossRef]

58. Brynjolfsson, E.; Horton, J.J.; Ozimek, A.; Rock, D.; Sharma, G.; TuYe, H.-Y. COVID-19 and Remote Work: An Early Look at US Data. Available online: https://www.nber.org/system/files/working_papers/w27344/w27344.pdf (accessed on 3 December 2020).

59. Larson, B.Z.; Vroman, S.R.; Makarius, E.E. A Guide to Managing Your (Newly) Remote Workers. Available online: https:/ / blackandmcdonaldhealth.com/wp-content/uploads/2020/03/HBR-A-Guide-to-Managing-Your-Newly-RemoteWorkers.pdf (accessed on 3 December 2020).

60. Angelucci, M.; Angrisani, M.; Bennett, D.M.; Kapteyn, A.; Schaner, S.G. Remote Work and the Heterogeneous Impact of COVID-19 on Employment and Health. Available online: https://www.nber.org/system/files/working_papers/w27749/w27749.pdf (accessed on 3 December 2020).

61. Gallacher, G.; Hossain, I. Remote Work and Employment Dynamics under COVID-19: Evidence from Canada. Can. Public Policy 2020, 46, S44-S54. [CrossRef]

62. Augustin, S. Designing to Beat Burnout and Encourage Engagement. In Proceedings of the Future Workspaces, Frankfurt am Main, Germany, 16-19 September 2020.

63. Newsham, G.R.; Veitch, J.A.; Zhang, M.Q.N.; Galasiu, A.D.; Henderson, I.S.; Thompson, A.J.L. Improving Organizational Productivity with Building Automation Systems. Available online: https://www.caba.org/wp-content/uploads/2020/07/2017 -CABA-Improving-Organizational-Productivity-with-Building-Automation-Systems-Full-Report.pdf (accessed on 19 January 2021).

64. Veitch, J.A.; Stokkermans, M.G.M.; Newsham, G.R. Linking Lighting Appraisals to Work Behaviors. Environ. Behav. 2013, 45, 198-214. [CrossRef]

65. Duque, L.; Costa, R.; Dias, Á.; Pereira, L.; Santos, J.; António, N. New Ways of Working and the Physical Environment to Improve Employee Engagement. Sustainability 2020, 12, 6759. [CrossRef]

66. Gerards, R.; de Grip, A.; Baudewijns, C. Do new ways of working increase work engagement? Pers. Rev. 2018, 47, 517-534. [CrossRef]

67. Veromaa, V.; Kautiainen, H.; Korhonen, P.E. Physical and mental health factors associated with work engagement among Finnish female municipal employees: A cross-sectional study. BMJ Open 2017, 7, e017303. [CrossRef]

68. Eguchi, H.; Shimazu, A.; Kawakami, N.; Inoue, A.; Nakata, A.; Tsutsumi, A. Work engagement and high-sensitivity C-reactive protein levels among Japanese workers: A 1-year prospective cohort study. Int. Arch. Occup. Environ. Health 2015, 88, 651-658. [CrossRef]

69. Nishi, D.; Suzuki, Y.; Nishida, J.; Mishima, K.; Yamanouchi, Y. Personal lifestyle as a resource for work engagement. J. Occup. Health 2016, 59, 17-23. [CrossRef] [PubMed]

70. Jindo, T.; Kai, Y.; Kitano, N.; Tsunoda, K.; Nagamatsu, T.; Arao, T. Relationship of workplace exercise with work engagement and psychological distress in employees: A cross-sectional study from the MYLS study. Prev. Med. Rep. 2020, 17, 101030. [CrossRef] [PubMed]

71. Munir, F.; Houdmont, J.; Clemes, S.; Wilson, K.; Kerr, R.; Addley, K. Work engagement and its association with occupational sitting time: Results from the Stormont study. BMC Public Health 2015, 15, 1-12. [CrossRef] [PubMed]

72. Roskams, M.; Haynes, B. Environmental demands and resources: A framework for understanding the physical environment for work. Facilities 2021, 39, 652-666. [CrossRef]

73. Otsuka, S.; Moriguchi, J.; Nishida, N.; Ohashi, F.; Saito, N.; Okuda, T.; Kawamata, K.; Matsudaira, K.; Tabuchi, M.; Oka, H. The effects of a two-minute original exercise program supported by the workplace unit on the workers' work engagement: The "Bipoji" exercise. J. Phys. Ther. Sci. 2020, 32, 410-413. [CrossRef]

74. Seppälä, P.; Mauno, S.; Kinnunen, M.-L.; Feldt, T.; Juuti, T.; Tolvanen, A.; Rusko, H. Is work engagement related to healthy cardiac autonomic activity? Evidence from a field study among Finnish women workers. J. Posit. Psychol. 2012, 7, 95-106. [CrossRef]

75. Brill, M. Using Office Design to Increase Productivity; Workplace Design and Productivity: Buffalo, NY, USA, 1984.

76. Sundstrom, E. Work Places: The Psychology of the Physical Environment in Offices and Factories, 1st ed.; Cambridge University Press: Cambridge, MA, USA, 1986.

77. Schullery, N.M. Workplace Engagement and Generational Differences in Values. Bus. Commun. Q. 2013, 76, 252-265. [CrossRef]

78. Kahn, W.A. Psychological conditions of personal engagement and disengagement at work. Acad. Manag. J. 1990, 33, 692-724. [CrossRef]

79. Robinson, D.; Perryman, S.; Hayday, S. The Drivers of Employee Engagement. Available online: https://www.employmentstudies.co.uk/system/files/resources/files/408.pdf (accessed on 24 January 2021).

80. Truss, C.; Soane, E.; Edwards, C.; Wisdom, K.; Croll, A.; Burnett, J. Working Life: Employee Attitudes and Engagement 2006; Chartered Institute of Personnel and Development: London, UK, 2007.

81. Brim, B. The Longer Workers Stay in Their Jobs, the More Disheartened They Become. Available online: https://news.gallup com/businessjournal/751/upend-trend.aspx (accessed on 25 March 2021). 
82. Albrecht, S.L. Employee engagement: 10 key questions for research and practice. In Handbook of Employee Engagement: Perspectives, Issues, Research and Practice, 1st ed.; Albrecht, S.L., Ed.; Edward Elgar Publishing: Northampton, MA, USA, 2010; pp. 3-19. [CrossRef]

83. CambridgeDictionary. Vigour. Available online: https://dictionary.cambridge.org/pl/dictionary/english/vigour (accessed on 12 February 2021).

84. Day, A.; Randell, K.D. Building a foundation for psychologically healthy workplaces and well-being. In Workplace Well-Being: How to Build Psychologically Healthy Workplaces, 1st ed.; Day, A., Kelloway, K., Hurrell, J.J., Jr., Eds.; Wiley Blackwell: Hoboken, NJ, USA, 2014; pp. 3-26.

85. Lovelace, K.J. Work and well-being: Stress and health in the workplace. In Indoor Work and Living Environments. Health, Safety and Performance; Harris, R.G., Moore, D.P., Eds.; Nova Science Publishers, Incorporated: Hauppauge, NY, USA, 2009 ; pp. $263-291$.

86. Isaac, F.W.; Ratzan, S.C. Corporate wellness programs: Why investing in employee health and well-being is an investment in the health of the company. In The Fulfilling Workplace: The Organization's Role in Achieving Individual and Organizational Health, 1st ed.; Cooper, C.L., Ed.; Taylor \& Francis Group: Farnham, VA, USA, 2016; pp. 321-334.

87. Bailey, C.; Madden, A.; Alfes, K.; Fletcher, L. The meaning, antecedents and outcomes of employee engagement: A narrative synthesis. Int. J. Manag. Rev. 2017, 19, 31-53. [CrossRef]

88. Schaufeli, W.B.; Bakker, A.B. UWES: Utrecht Work Engagement Scale. Preliminary Manual; Department of Psychology, Utrecht University: Utrecht, The Netherlands, 2003.

89. Shirom, A. Feeling vigorous at work? The construct of vigor and the study of positive affect in organizations. Res. Organ. Stress Well-Being 2003, 3, 135-165.

90. May, D.R.; Gilson, R.L.; Harter, L.M. The psychological conditions of meaningfulness, safety and availability and the engagement of the human spirit at work. J. Occup. Organ. Psychol. 2004, 77, 11-37. [CrossRef]

91. Harter, J.K.; Schmidt, F.L.; Hayes, T.L. Business-unit-level relationship between employee satisfaction, employee engagement, and business outcomes: A meta-analysis. J. Appl. Psychol. 2002, 87, 268-279. [CrossRef] [PubMed]

92. Saks, A.M. Antecedents and consequences of employee engagement. J. Manag. Psychol. 2006, 21, 600-619. [CrossRef]

93. AON. Working form Home: Implementing a Permanent Remote-Work Policy Post-Coronavirus. Available online: https:/ / insights-north-america.aon.com/enhancing-wellbeing/aon-working-from-home-implementing-a-permanentremote-work-policy-post-coronavirus-whitepaper (accessed on 17 February 2021). 